\title{
Inhibitory and Emotional Control Deficits as Mediators between Protective Factors and Symptoms of Problem Behaviors in Delinquency
}

\author{
Abdul Rahman Ahmad Badayai, Wan Shahrazad Wan Sulaiman, Rozainee Khairudin
}

\begin{abstract}
Much research has examined the role of inhibitory and emotional controls in the educational setting with an emphasis on learning and coaching. However, they underestimate the effect and role of inhibitory and emotional controls in delinquent behaviors. Therefore, the current study examined the impact of inhibitory and emotional controls as mediators between protective factors and symptoms of problem behaviors. Respondents of the survey consisted of 404 delinquents convicted of several crimes such as armed robbery, drug trafficking, and drug use, gang fights, rape, homicide, and out of control behaviors. Three psychological instruments; Developmental Assets Questionnaire-Malaysian Version (DAQ-MV), Behavior Rating Inventory of Executive Function-Self Report (BRIEF-SR) and Achenbach System of Empirical Behavior Assessment- Youth Self-Report (ASEBA-YSR) were used to collect data. The result showed that there was no evidence that planning/decision making influenced rule-breaking behavior independent of its effect on inhibitory and emotional controls ( $\left.c^{\prime}=-.113, p=.062\right)$. On the contrary, there was evidence that resistance skill/resilience influenced rule-breaking behavior independently of its effect on inhibitory and emotional controls $\left(c^{\prime}=-.204, p=.000\right)$. Morality and religiosity also have been found to influence rule-breaking behavior independently of its effect on inhibitory and emotional controls $\left(c^{\prime}=-.231, p=.000\right)$. The results contributed to an enhancement of early prevention strategy based on executive function, especially in institutions like prison and rehabilitation school.
\end{abstract}

Index Terms: executive function, developmental assets, rule-breaking behavior, at-risk youth.

\section{INTRODUCTION}

Adolescents in the literature have been regarded as the most precious and priceless assets of the nation-building. The well-being of one society very much depends on the well-educated, well-adjusted, and responsible young people. The wellness, stability, and strength of adolescent rely much on the ability of leaders and elders to ensure how much our young people, especially young generation are prepared to face the known and unknown challenges throughout their life. According to Hall, through the developmental process, adolescence has often regarded and viewed as a storm and

Revised Manuscript Received on September 25, 2019

Abdul Rahman Ahmad Badayai, Centre of Human and Societal Wellbeing, Faculty of Social Sciences and Humanities, The National University of Malaysia, Bangi Selangor, Malaysia.

Wan Shahrazad Wan Sulaiman, Centre of Human and Societal Wellbeing, Faculty of Social Sciences and Humanities, The National University of Malaysia, Bangi Selangor, Malaysia.

Rozainee Khairudin, Centre of Human and Societal Wellbeing, Faculty of Social Sciences and Humanities, The National University of Malaysia, Bangi Selangor, Malaysia. stress period as well as uproar from various aspects such as social, physical, emotional, cognitive, psychological and to the physiological changes, which much-affecting adolescents developmental stages [1]. Due to these developmental changes and reactions, some adolescents are able to succeed in growth positively. However, the rest of them may struggle and often engaged in problem behaviors.

In Malaysia, the prevalence of male and female adolescents involved in conduct problems or problem behaviors are much more significant in the manifestation of overt behaviors than covert behaviors. Males are reported having higher engagement in overt problem behaviors such as physical aggression, violence, group fights, and substance use [2],[4]. On the other hand, females are more likely to be characterized by covert behaviors, such as stealing or running away [5],[6]. Moreover, conduct problem or problem behaviors in females are linked to several adverse outcomes, such as early teenage pregnancy and abortion [5]. Females are more responsive to peer's pressure, including feelings of guilt than males. These different major pathways could be seen in a rehabilitation center, disciplinary cases in school, and even to the legal and illegal crimes convicted by young people.

The question of what constitutes problem behaviors or conduct problems is very complicated. Wicks-Nelson \& Israel stated that problem behaviors displayed by adolescents are problems resulting from transactions among different variables such as the structure of biological functioning, the transmission of genetic, stability and response of emotion, cognition, and social interaction [7],[8]. Other numerous aspects, such as the immediate environment would also play an intricate role in constraining or displaying psychological and behavioral functioning. Further, Wicks-Nelson \& Israel emphasized on two concerns as the significant attention to comprehend the nature of problem behaviors or conduct problems [8]. Firstly, whether it applies to discount the social context and place the focus of problem behaviors of adolescent entirely within the individual, secondly to put emphasis on the risk and protective factors from the environmental stressors such as family, school, and immediate intact of the community as a whole.

Besides, other factors such as cognitive function, intelligence and cognitive deficits [9] are also variables that very common and often neglected among adolescent with conduct problems as well as those diagnosed with conduct disorders [7],[8]. Particularly those with early-onset who have intelligence quotients (IQ) one standard deviation below the mean and also deficits in verbal reasoning and executive functioning [10]. The manifestation of conduct 
problems or problem behaviors much involves the cognitive process, such as executive function [11]. Adolescents with conduct problems and conduct disorders may manifest difficulties concerning one's ability to plan and organize, inhibit a pre-potent response, or shift between tasks [12],[13]. It is true even after taking into account other variables such as race, socioeconomic status (SES), and education. Therefore, it is essential to note that deficits in IQ and executive function such as inhibitory and emotional control deficits are only one piece of the puzzle [14], and the influence on the development of conduct problems as well as other problem behaviors increased during transactional processes with environmental factors.

In relation to the study, according to Bronfenbrenner, Ecological Systems Theory assumes that individual behaviors are the results of the multi-interactions between one's environment and their immediate systems; microsystems, mesosystems, exosystems, macrosystems, and chronosystems [15]. The environment includes immediate biological parents, family members, neighbors, school, and community. Far beyond this assumption is the degree to which reciprocal interaction occurred between all systems starting from microsystem to macrosystem and its continual state development [16]. Therefore, problem behaviors are much relates to the interactions between the systems.

The current study seeks to examine the mediating effect of executive function between protective factors and symptoms of problem behaviors with an emphasis on the developmental psychopathology perspective and approach as an associate to the more conventional clinical approach. Moreover, this perspective and approach assume that problem behaviors of young people, such as rule-breaking behavior and aggression must be viewed within a developmental context. It is believed that all healthy development and disturbing behavior are related somehow to a dynamic pathway of experience and growth, in which connected to one's past, present, and future behavior.

Therefore, three main hypotheses were developed to be tested accordingly; hypothesis 1: There are significant mediating effects of inhibitory and emotional controls deficit in the relationships between planning/decision making and rule-breaking behavior. Hypothesis 2: There are significant mediating effects of inhibitory and emotional control in the relations between resistance skill/resilience and rule-breaking behavior, and hypothesis 3: There are significant mediating effects of inhibitory and emotional controls deficit in the relationships between morality/religiosity and rule-breaking behavior.

\section{METHODOLOGY}

\section{A. Research Design}

A cross-sectional design with a survey method was employed in this research. Stratified random sampling was used among 404 respondents which comprises of 280 male and 124 female adolescents. The unequal sample size of each stratum was required to the population size of the stratum. Therefore, each location, gender, types of cases has different sampling fractions. The results were analysed by using PROCESS MACRO analysis to measure the mediator interaction between protective factors and symptoms of problem behaviors. The respondents were among juvenile

delinquents from various institutions in Malaysia; Tunas Bakti school, Kajang prison, and Henry Gurney school. They were convicted of different juvenile offenses such as stealing, drug use, fighting, murder, rape, and out of control behaviors. The respondents' ages ranged from 13-year-olds to 18-year-olds.

\section{B. Instruments}

\section{Behavior Rating Inventory of Executive Function-Self Report (BRIEF-SR)}

The Behavior Rating Inventory of Executive Function-Self Report (BRIEF-SR) is an assessment of executive function behaviors for children and adolescents ages 5-18 [17]. It consists of 86 items. It has very good reliability, with high test-retest reliability (rs - .88 for teachers, .82 for parents), internal consistency (alphas - .80 - .98), and moderate correlations between parent and teacher ratings (rs - .32 - .34). It is also used to evaluate children and adolescents with a variety of disorders and disabilities including pervasive developmental disorders, Tourette syndrome, learning disabilities, high-functioning autism, traumatic brain injury, and low birth weight baby [17].

\section{Achenbach System of Empirical Behavior Assessment-Youth Self Report (ASEBA-YSR)}

Achenbach System of Empirical Behavior Assessment (ASEBA-YSR) is an assessment to rate a child's competencies and problem behaviors [18]. It consists of 140 items. The ASEBA-YSR construct measured several domains, such as Aggression, Hyperactivity, Bullying, Conduct Problems, Defiance, and Violence. There are high reports on the psychometric information on the YSR; test-retest value is 0.95 to 1.00 , inter-rater reliability value is 0.93 to 0.96 , and internal consistency value is 0.78 to 0.97 [18].

\section{Developmental Assets Questionnaire-Malaysian Version $(D A Q-M V)$}

The Developmental Assets Questionnaire-Malaysian Version (DAQ-MV) is an assessment to measure an individual child's protective factors and risk factors. It consists of two domains, which are internal assets and external assets. Internal assets comprise of 12 constructs (54 items); achievement motivation, school engagement, caring/positive value, integrity, planning and decision making, interpersonal competence, resistance skill/resilience, self-esteem, a sense of purpose, positive view of personal future, morality/religiosity, and positive feeling. On the other hand, external assets comprise of nine constructs including family support, positive family communication, other adult relationship, family boundaries, a caring neighborhood, hopes and expectations, positive peer influence, religious community, physical, emotional and social safety. The Developmental Assets Questionnaire-Malaysian Version (DAQ-MV) showed relatively higher values ranged between 0.87 Cronbach's Alphas to 0.88 Cronbach's Alpha [19]. 


\section{RESULTS AND DISCUSSION}

PROCESS MACRO analysis was used to measure the mediating effects of inhibitory and emotional controls. Thus, the bootstrapping of 10,000 was selected to measure the purported hypotheses.

Hypothesis 1: There are significant mediating effects of inhibitory and emotional controls in the relationships between planning/decision making and rule-breaking behavior

From a parallel multiple mediation analysis conducted using ordinary least squares path analysis; planning/decision making indirectly influenced rule-breaking behavior through its effect on executive function. As can be seen in Figure 1 and Table 1, respondents who scored lower on planning/decision making would express higher the inhibitory problem behavior (a1 = -.188), and respondents who scored higher on the inhibitory problem would highly engage in rule-breaking behavior $(\mathrm{b} 1=.672)$. On the contrary, respondents who scored lower on planning/decision making would express higher emotional control problem $(\mathrm{a} 2=-.260)$. However, respondents who scored higher on emotional control problem does not show any rule-breaking behavior $(\mathrm{b} 2=.063)$. A bias-corrected bootstrap confidence interval for the indirect effect $(\mathrm{ab}=-.143)$ based on 10,000 bootstrap samples was entirely above zero $(-.228$ to -.069$)$. Thus, there was no evidence that planning/decision making influenced rule-breaking behavior independently of its effect on inhibitory control and emotional control ( $c^{\prime}=-.113, \mathrm{p}=.062$ ).

The inhibitory and emotional control mediates the relationships between planning/decision making and rule-breaking behavior. The mediating effect can be explained through cognitive-ecological concepts. The cognitive-ecological conceptualization of adolescent behavior uses a multifactor framework that emphasizes the confluence of individual, environmental, and situational factors [20]. At the individual factor, it includes temperament, arousal, brain structures, and other personal characteristics. While at the environmental factor, it includes family, neighborhood, and social components.

Moreover, at the situational factor, it includes perceptions, mood, stress, and other immediate contextual characteristics. These multi-factors of individual, environmental, and situational interact over time to shape and maintain cognitive structures that subsequently influence emotions and guide behaviors. In the cognitive-ecological conceptualization of behavior, social cognition affects both individual behavior and intended intervention. Adolescent's social contexts and experiences produce distinct cognitive styles through practical experiences, derived knowledge, and memory process that become the characteristic of individual adolescent throughout development.

Although these cognitive patterns temporarily can shift personal tendencies and environmental cues, adolescents would ultimately internalize and replicate general orientations toward distinct cognitive styles across various social situations [22]. The adolescent would attend to pertinent social information, act according to their personality temperament, causal attribution, and learn from environmental consequences. Subsequently, reproduce those selected responses that attain or approximate their intended goals. Thus, adolescents develop and internalize scripts (i.e., response patterns for given situations) that facilitate selecting and processing pertinent information and then generating appropriate behaviors in social contexts [22], [23].

Table 1: Regression Coefficient, Standard Errors, and Model Summary Information for the Executive Function Parallel Multiple Mediator Model between Planning/Decision Making and Rule Breakin Behavior Depicted in Figure 1.

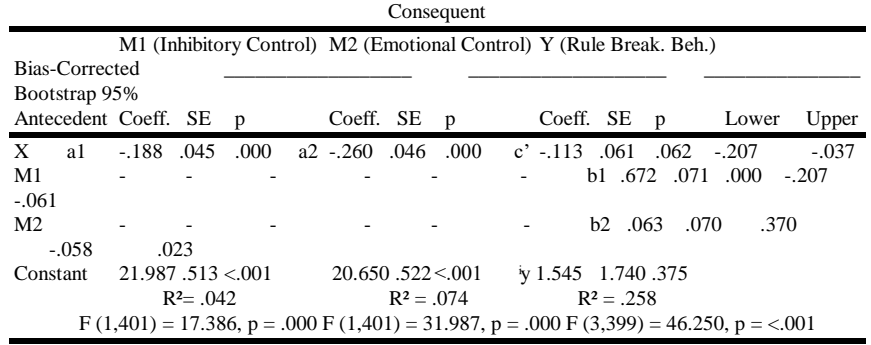

\section{INHIBITORY CONTROL}

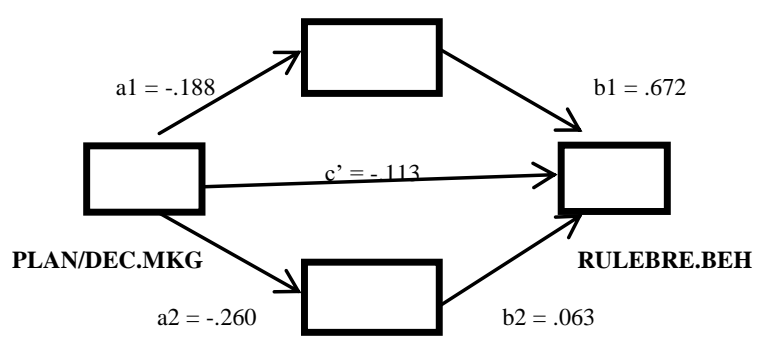

EMOTIONAL CONTROL

Fig 1: A statistical diagram of the parallel multiple mediator models for the executive function studies between planning/decision making and rule-breaking behavior.

Hypothesis 2: There are significant mediating effects of inhibitory and emotional controls in the relationships between resistance skill/resilience and rule-breaking behavior

From a parallel multiple mediation analysis conducted using ordinary least squares path analysis; resistance skill/resilience did not indirectly influence rule-breaking behavior through its effect on executive function. As can be seen in Figure 2 and Table 2, respondents who scored lower on-resistance skill/resilience would express higher inhibitory problem behavior $(\mathrm{a} 1=-.201)$, and respondents who scored higher on the inhibitory problem would highly engage in rule-breaking behavior $(\mathrm{b} 1=.635)$. On the contrary, respondents who scored lower on-resistance skill/resilience expressed higher emotional control problem $(\mathrm{a} 2=-.185)$, and respondents who scored higher on emotional control problem, however, scored lower on rule-breaking behavior $(\mathrm{b} 2=.055)$. A bias-corrected bootstrap confidence interval for the indirect effect $(\mathrm{ab}=$ -.138) based on 10,000 bootstrap samples was entirely above zero (-.205 to -.077). Thus, there was evidence that resistance skill/resilience influenced rule-breaking behavior independently of its effect on inhibitory control and emotional control ( $\left.c^{\prime}=-.204, \mathrm{p}=.000\right)$.

It indicated that inhibitory and emotional controls did not mediate the relationships between resistance skill/resilience and rule-breaking behavior. Resistance skill/resilience is independent of executive function. This result can also be explained through the nature of the executive function by which adolescent's context of development reinforced the process and progress of the 
development of a type of script, it changed over time, and it is reinforcement [23]. For example, adolescents with excitable temperament, exposed to external causal attributions for violent incidents, and consistent receiving reward of peer respect and personal safety for aggressive behavior may form general orientations that are hypersensitive and prone toward peer conflict. As a result, these adolescents would most likely internalize aggressive scripts for dealing with perceived and actual hostility from other young people in their schools and neighborhoods [23]. Although individual behaviors and contextual dynamics can vary over time, these adolescent scripts and their situational sources can be valuable targets for intervention given that they represent the intersection of predisposing cognitive style and reinforcement by the contextual influences over time.

Table 2: Regression Coefficient, Standard Errors, and Model Summary Information for the Executive Function Parallel Multiple Mediator Model between Resistance Skill/Resilience with Rule-Breaking Behavior Depicted in Figure 2.

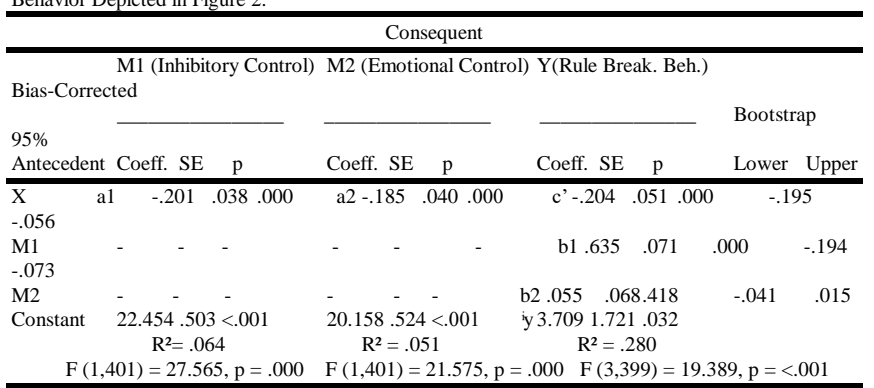

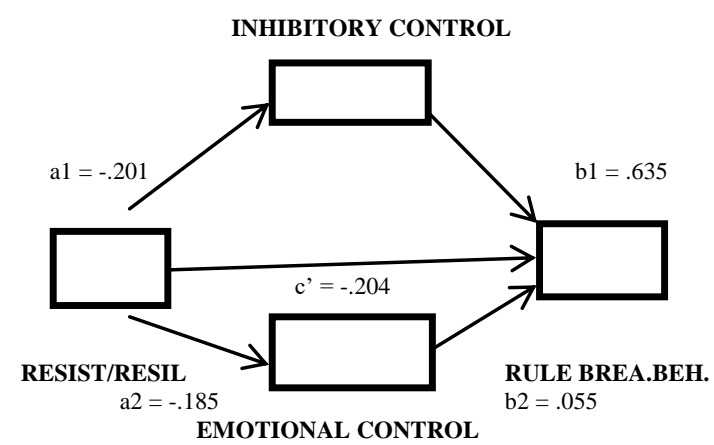

Fig 2: A statistical diagram of the parallel multiple mediator models for the executive function studies between resistance skill/resilience and rule-breaking behavior.

Hypothesis 3: There are significant mediating effects of inhibitory and emotional controls in the relationships between morality/religiosity and rule-breaking behavior

From a parallel multiple mediation analysis conducted using ordinary least squares path analysis; morality/religiosity does not indirectly influence rule-breaking behavior through its effect on executive function. As can be seen in Figure 3 and Table 3 respondents who scored lower on morality/religiosity would not express higher inhibitory problem behavior $(\mathrm{a} 1=$ -.053), and respondents who scored higher on the inhibitory problem would also do not engaged in rule-breaking problem behavior $(\mathrm{b} 1=.651)$. On the contrary, respondents who scored lower on morality/religiosity was also does not expressed higher emotional control problem $(\mathrm{a} 2=-.032)$, and respondents who scored higher on emotional control problem, however, does engage in rule-breaking problem behavior (b2

$=-.116)$. A bias-corrected bootstrap confidence interval for the indirect effect $(\mathrm{ab}=-.031)$ based on 10,000 bootstrap samples was entirely above zero (-.087 to -.026). Thus, there was evidence that morality/religiosity influenced rule-breaking behavior independently of its effect on inhibitory control and emotional control ( $\left.\mathrm{c}^{\prime}=-.231, \mathrm{p}=.000\right)$.

Again, inhibitory and emotional controls did not mediate the relationships between morality/religiosity and rule-breaking behavior. The morality/religiosity seems to be independent of its influencing rule-breaking behavior. The morality/religiosity aspects of what is right and wrong can also be understood through the focus on changing adolescent tendencies as well as environmental factors are being increasingly advanced by several theorists, practitioners, and researchers [21], [22]. For example, Dodge \& Pettit presented a biopsychosocial model that is congruent with notions of social cognition and scripts [22]. This model argues that (1) biological dispositions, social context, and early and ongoing life experience of developing youth lead to distinct social knowledge comprising related cognitive-emotional phenomena (e.g., relational schema guiding declarative and procedural information processing, and social scripts reflecting beliefs about how social events occur in daily life); (2) children memorize social knowledge about their surrounding world and used as a guide for subsequent behavior; (3) children and adolescents use this social knowledge to guide information processing and generate related specific cognitive, emotional, and behavioral responses to social stimuli (e.g., peers, parents, teachers); and (4) these social information processing patterns mediate effects of prior experiences on subsequent behaviors and, consequently, offer an essential understanding of the morality/religiosity factors.

Table 3: Regression Coefficient, Standard Errors, and Model Summary Information for the Executive Function Parallel Multiple Mediator Model between Morality/Religiosity and Rule-Breaking Behavior Depicted in Figure 3 .

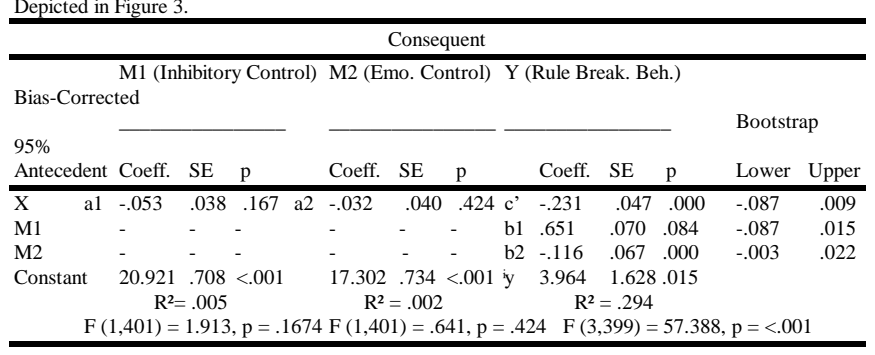


INHIBITORY CONTROL

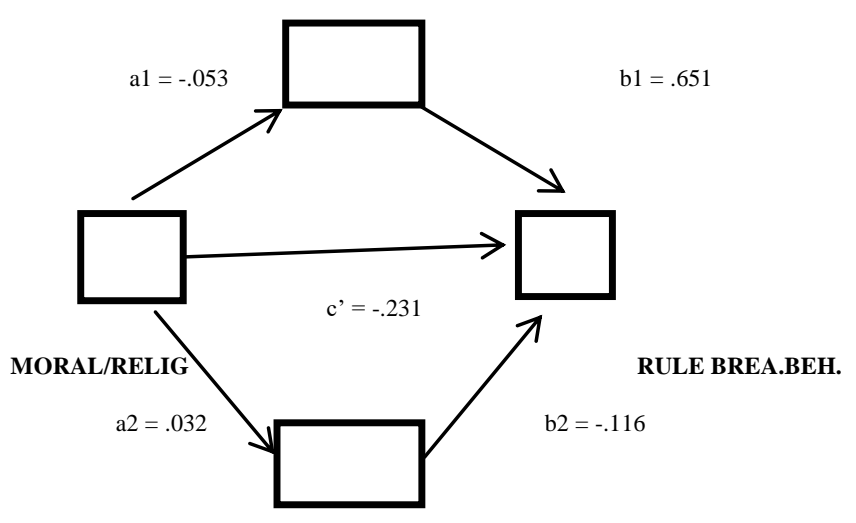

EMOTIONAL CONTROL

Fig 3: A statistical diagram of the parallel multiple mediator models for the executive function studies between morality/religiosity and rule-breaking behavior.

The findings would have led to a great impact on the theoretical foundation and psychological ground in developmental psychology. The role of inhibitory control and emotional control deficits have now a powerful element in understanding one's behavior especially for juvenile delinquents and other behavior that's related or fall into the at-risk category. Moreover, at-risk adolescents or problem behavior adolescents with the executive dysfunction problem have been theorized weakening in their inhibitory control ability and poor in emotional control. In a theoretical framework, it is imperative to comprehend the structure of executive function especially inhibitory control and emotional control in the expression of overt and covert behaviors. Executive dysfunction regulates much of one's behavior on a daily basis. Thus, new perspective on juvenile delinquents or problem behavior in adolescents could have emerged in leading the way through a better perspective and wider understanding.

\section{CONCLUSION}

In conclusion, there was no evidence that planning/decision making influenced rule-breaking behavior independently of its effect on inhibitory control and emotional control. Also, there was evidence that resistance skill/resilience influenced rule-breaking behavior independently of its effect on inhibitory control and emotional control. Moreover, there was evidence that morality/religiosity influenced rule-breaking behavior independently of its effect on inhibitory control and emotional control. The results of the present study are supported by previous study. It is the cognitive processes of executive dysfunction that play a crucial role in mediating the relationships between protective factors and symptoms of problem behaviors. Individual dispositions, life experiences, and exposure to adversities may contribute to the development of rule-breaking and aggressive behaviors because an individual adolescent develops a certain belief of social knowledge about their world. The above condition would lead to various interpretations and responses to cognitive processes. In the absence

of executive functioning or deficit, juvenile delinquents may interpret and response their social events undesirably. Thus, lead to further engagement in aggression and rule-breaking behaviors. The evidence proposes in the present study that there is no single path through which individual experiences exerts an effect on rule-breaking and aggression of symptoms of problem behaviors. Thus, a mediating variable such as inhibitory control and emotional control deficits exerts their effects between protective factors and symptoms of problem behaviors.

\section{ACKNOWLEDGMENT}

Authors would like to show the gratitude to CRIM UKM for the research grant GGPM-2018-026. This research was fully supported by the above mentioned research grant, as without the grant, it was very impossible to complete this research.

\section{REFERENCES}

[1] Hall, G.S. (1904). Adolescence: In psychology and its relation to physiology, anthropology, sociology, sex, crime, religion, and education. (vol I \& II). New Jersey: Prentice-Hall.

[2] Mohamed, M. Z., Marican, S., Elias, N., \& Don, Y. (2008). Pattern of substance and drug misuse among youth in Malaysia. Jurnal Antidadah Malaysia, 3,1-56.

[3] Hammond, D., Kin, F., Prohmmo, A., Kungskulniti, N., Lian, T. Y., Sharma, S. K., Buppha, S., Borland, R., \& Fong, G. T. (2008). Patterns of smoking among adolescents in Malaysia and Thailand: Findings from the International Tobacco Control Southeast Asia Survey. Asia-Pacific Journal of Public Health /Asia-Pacific Academic Consortium for Public Health, 20(3), 193-203. Doi.org/10.1177/1010539508317572

[4] Lim, K.H., Sumarni, M.G., Kee, C.C., Christopher, V.M., Noruiza Hana, M., Lim, K.K., \& Amal, N.M. (2010). Prevalence and Factors Associated With Smoking Among Form Four students In Petaling District, Selangor, Malaysia. Tropical Biomedicine, 27(3), 394-403.

[5] Lee, W.E., Wadsworth, M.E., \& Hotopf, M. (2006). The protective role of trait anxiety: A longitudinal cohort study. Psychological Medicine, $36,345-351$.

[6] Omar, Hatim A., Ventegodt, S., \& Merrick, J. (2010). Quality of Life and Adolescents in Rural Kentucky. Pediatrics Faculty Publications. Paper $115 . \quad$ Retrieved http://uknowledge.uky.edu/pediatrics_facpub/115

[7] Wicks-Nelson, R., \& Israel, A.C. (2009). Abnormal child and adolescent psychology. ( $7^{\text {th }}$ Ed.).Pearson Education: New Jersey.

[8] Wicks-Nelson, R., \& Israel, A.C. (2013). Abnormal child and adolescent psychology. ( $8^{\text {th }}$ Ed.).Pearson Education: New Jersey.

[9] Kendall, P.C. (2006). The Present and Future of Clinical Psychology. Clinical Psychology: Science and Practice, 13(3), 203-204. doi: 10.1111/j.1468-2850.2006.00024.x

[10] Steinberg, L. (2007). Adolescence (8th ed.). New York: McGraw-Hill

[11] Steinberg, L. (2010). Risk taking in adolescence: New perspectives from brain and behavioral science. 2004. Edited by Dodge, K. A. In Currents directions in child psychopathology. Boston: Pearson.

[12] Reyna, V.F., \& Farley, F. (2006). Risk and Rationality in Adolescent Decision Making Implications for Theory, Practice, and Public Policy. Psychological Science in the Public Interest, 7(1), 1-44.

[13] Millstein, S.G. \& Halpern-Felsher, B.L. (2002). Judgments about Risk and Perceived Invulnerability in Adolescents and Young Adults. Journal of Research on Adolescence, 12(4), 399-422. doi: 10.1111/1532-7795.00039.

[14] Iselin, A.M. \& Decoster, J. (2009). Reactive and proactive control in incarcerated and community adolescents and young adults. Cognitive Development, 24(2), 192-206.

[15] Bronfenbrenner, U. (1979). The ecology of human development Experiments in nature and design. Cambridge, MA: Harvard University Press. 
[16] Tudge, J.R.H., Mokrova, I., Hatfield, B.E., \& Karnik, R.B. (2009). Uses and Misuse of Bronfenbrenner's Bioecological Theory of Human Development. Journal of Family Theory \& Review, 1, 198-210.

[17] Guy, S.C., Isquith, P.K., \& Gioia, G.A. (2004). Behavior rating inventory of executive function-self report version: professional manual. Florida: PAR.

[18] Achenbach, T.M., \& Rescorla, L.A. (2001). Manual for the ASEBA School-Age Forms \& Profiles. Burlington, VT: University of Vermont, Research Center for Children, Youth \& Families.

[19] Nor Ba'yah, A.K., Samsudin, A.R., Mustapha, Z., Mutalib, A., Hanida, M., \& Kee, C.P. (2012). External assets as predictors of positive emotions among at-risk youth in Malaysia. Asian Social Work and Policy Review, 6 (3), 203-217.

[20] Guerra, N.G., Boxer, P., \& Kim, T. (2005). A cognitive-ecological approach to serving students with emotional and behavioral disorders: Application to aggressive behavior. Behavioral Disorders, 30, $277-288$.

[21] Crick, N.R., \& Dodge, K.A. (1994). A review and reformulation of social information-processing mechanisms in children's social adjustment. Psychological Bulletin, 115, 74-101.

[22] Dodge, K.A., \& Pettit, G.S. (2003). A biopsychosocial model of the development of chronic conduct problems in adolescence. Developmental Psychology, 39, 349 - 371.

[23]Dodge, R.N. (2010). Childhood emotional maltreatment and later Intimate relationships: Themes from the empirical literature. Journal of Aggression, Maltreatment and Trauma, 19(2), 224-242.

\section{AUTHORS PROFILE}

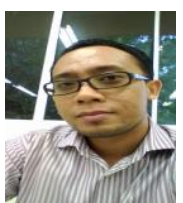

Abdul Rahman Ahmad Badayai Dr. Abdul Rahman Ahmad Badayai is a senior lecturer at Center of Human and Societal Well-Being, Faculty of Social Sciences and Humanities, The National Univeristy of Malaysia, Bangi Selangor, Malaysia. He received his Doctor of Philosophy in Psychology from The National University of Malaysia. His field of specialization is developmental psychology. Among his research interests are application of developmental psychology in infant and preschool assessment (prevention and intervention), at-risk youth prevention and intervention (bullying, early sexual behavior, substance use/misuse/abuse, violence and aggression, suicide, and school dropout), children and youth developmental assets, mental health prevention and intervention, sexual and gender-based violence. He has published his works in various journals; Journal Psychology Malaysia (JPM), Akademika, Journal of Social Sciences and Humanities (e-bangi), American Journal of Applied Psychology, International Journal of Psychology, and Journal of Education and Social Sciences.

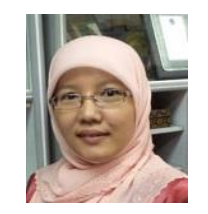

Wan Shahrazad Wan Sulaiman Dr. Wan Shahrazad Wan Sulaiman is an associate professor at Center of Human and Societal Well-Being, Faculty of Social Sciences and Humanities, Universiti Kebangsaan Malaysia, Malaysia. She received her Doctor of Philosophy in Psychology from International Islamic University Malaysia. Her field of specialization is psychometrics. Among her research interests are application of psychological tests, adaptation and standardization of psychological tests among prisoners for parole evaluation, psychological profile of drug addicts, personality profile of adolescents and juvenile delinquents, and assessment of critical thinking ability among university students. She has published her works in Journal Psychology Malaysia, Akademika, Pertanika Journal of Social Sciences and Humanities, World Applied Sciences Journal, American Journal of Applied Science and several other journals.

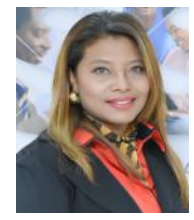

Rozainee Khairudin Dr. Rozainee Khairudin is an associate professor at Center of Human and Societal Well-Being, Faculty of Social Sciences and Humanities, Universiti Kebangsaan Malaysia, Malaysia. She received her Doctoral degree and Masters of Science degree in Cognitive Science at University of Birmingham, United Kingdom. Her Bachelor degree is in Psychology from Univeristy of Reading, United Kingdom. Her research interests include mind-set, false memory, and effects of emotion on cognition. 